\title{
A UTILIZAÇÃO DE TECNOLOGIAS DIGITAIS NAS PRÁTICAS PEDAGÓGICAS NO CONTEXTO DA PANDEMIA DA COVID-19
}

\author{
Adrianne Veras de Almeida ${ }^{1}$ \\ Adrielle Veras de Almeida ${ }^{2}$ \\ Maria Beatriz de Oliveira Castro ${ }^{3}$ \\ Maria Amanda de Lima Paulo ${ }^{4}$
}

\begin{abstract}
RESUMO
Este trabalho teve como objetivo investigar as Tecnologias Digitais da Informação e Comunicação (TDICs) utilizadas pelos professores, bem como as dificuldades enfrentadas para a garantia da continuação do ensino-aprendizagem durante a pandemia da Covid- 19. Trata-se de um estudo de caso, cujos dados foram coletados por meio de um questionário on-line desenvolvido na plataforma Google Forms, sendo divulgado publicamente por alguns meios de comunicação, tais como: Instagram, Facebook, WhatsApp e e-mail. O período de coleta dos dados ocorreu entre os dias 6 de maio e 18 de junho de 2021, na qual se obtiveram 158 respostas. O questionário supracitado foi dividido em três seções, a saber: na primeira, continha o Termo de Consentimento Livre e Esclarecido (TCLE); na segunda, possuía seis questões referentes à atuação profissional (localização e profissão) do docente; e na terceira, a apresentação das 9 questões relacionadas ao uso de tecnologias digitais e educacionais em sala de aula no período da pandemia, totalizando 15 questões com perguntas abertas, fechadas e de múltipla escolha, o que possibilitou, dessa forma, uma abordagem dos dados tanto em aspectos quantitativos como qualitativos. Os resultados obtidos indicaram que as principais dificuldades citadas foram a falta de capacitação e de um profissional da área de Licenciatura em Computação/Informática e, ainda, a adequação dessas tecnologias ao contexto das aulas remotas.
\end{abstract}

Palavras-chave: Educação. TDIC. Ensino remoto.

\footnotetext{
${ }^{1}$ Mestrado em Ciência da Computação pela Universidade Federal do Pará. E-mail: verasadrianne3@gmail.com ${ }^{2}$ Pós-Graduação em Informática na Educação pelo Instituto Federal de Educação, Ciência e Tecnologia do Espírito Santo. E-mail: adrielle.veras@gmail.com

${ }^{3}$ Pós-Graduação em Sistemas de Informação pela Faculdade Venda Nova do Imigrante. E-mail: beatriz.kstro. oli@gmail.com

${ }^{4}$ Graduação em Licenciatura em Computação pela Universidade Federal Rural da Amazônia. E-mail: amandalima0525@gmail.com
} 


\title{
THE USE OF DIGITAL TECHNOLOGIES IN PEDAGOGICAL PRACTICES IN THE CONTEXT OF THE COVID-19 PANDEMIC
}

\begin{abstract}
This work aimed to investigate the Digital Information and Communication Technologies (ICT) used by teachers, as well as the difficulties faced to ensure the continuation of the teaching and learning process during the COVID-19 pandemic. This is a case study, in which the data was collected through an online questionnaire developed on Google Forms platform, being publicly announced via: Instagram, Facebook, Whatsapp, and e-mail. The data collection period occurred between May 6 and June 18, 2021, obtaining 158 replies. The research questionnaire was divided into three sections: the first contained the Free and Informed Term of Consent (TCLE), the second had six questions related to the professional performance of the teacher (location and profession), and the third was composed of nine questions related to the use of digital and educational technologies in the classroom during the pandemic period, totaling 15 questions with open, closed and multiple choice questions, thus enabling a quantitative as well as qualitative approach to the data. The results indicated that the main difficulties mentioned were the lack of training, a professional degree in Computing / Informatics and adequacy of these technologies to the context of remote classes.
\end{abstract}

Keywords: Education. Digital Information and Communication Technologies. Remote teaching.

\section{EL USO DE TECNOLOGÍAS DIGITALES EN PRÁCTICAS PEDAGÓGICAS EN EL CONTEXTO DE LA PANDEMIA - COVID-19}

\section{RESUMEN}

Este trabajo tuvo como objetivo investigar sobre las Tecnologías Digitales de la Información y la Comunicación (TDIC), utilizadas por los docentes, así como las dificultades que se enfrentan para garantizar la continuación de la enseñanza del aprendizaje durante la pandemia - COVID 19. Se trata de un caso de estudio, cuyos datos fueron recogidos a través de un cuestionario online desarrollado en la plataforma Google Forms, siendo divulgado públicamente a través de medios como: Instagram, Facebook, WhatsApp y Email. El periodo de recolección de datos ocurrió entre el 6 de mayo y el 18 de junio de 2021, obteniendo 158 respuestas recibidas. El cuestionario de investigación se dividió en tres secciones: la 
primera contenía el Formulario de Consentimiento Informado (TCLE), la segunda tenía seis preguntas relacionadas con el desempeño profesional (ubicación y profesión) del docente y la tercera estaba compuesta por nueve preguntas relacionadas con el uso de las tecnologías digitales y educativas en el aula durante el período de pandemia, totalizando 15 preguntas con preguntas abiertas, cerradas y de opción múltiple, lo que permite un enfoque de los datos cuantitativos y cualitativos. Los resultados indicaron que las principales dificultades mencionadas fueron la falta de formación, un título profesional en Informática / Informática y la adecuación de estas tecnologías al contexto de las aulas a distancia.

Palabras clave: Educación, Tecnologías de la Información y las Comunicaciones Digitales. enseñanza remota.

\section{INTRODUÇÃO}

Com o advento das Tecnologias Digitais da Informação e Comunicação (TDICs), como internet, Ambientes Virtuais de Aprendizagem (AVAs), plataformas de videoconferência, e, ainda, considerando o cenário pandêmico mundial em que se vive, causado pela Covid-19, os recursos tecnológicos exemplificados vêm sendo adotados e utilizados em grande escala, pois possibilitam novos espaços de aprendizagem de modo que alteram as metodologias de ensino, posto que alunos e professores estão diante de um momento no qual é exigido um outro modo de ensinar e aprender, tendo como referência o Ensino Remoto Emergencial (ERE), modelo ao qual muitos não estavam familiarizados e sequer preparados. (BARANAUSKAS; VALENTE, 2013).

De acordo com Oliveira, Mello e Franco (2020), faz-se necessário não somente inserir e utilizar as várias tecnologias, mas sim encontrar a forma mais adequada de integrá-las aos procedimentos metodológicos, tendo como premissa o desenvolvimento e o rendimento do aluno, afinal, o mesmo objetivo tanto do processo educativo virtual como o do presencial é que haja aprendizagem por parte do estudante. Portanto, no meio virtual, podem surgir algumas dificuldades, sendo que professores e alunos precisam dispor de uma infraestrutura mínima que permeia aspectos, como celular, notebook, internet, predisposição dos mesmos, principalmente, do aluno, entre outros. Requer, também, docentes que conheçam e tenham um contato aprofundado com as tecnologias digitais, 0 que pode ser adquirido por meio de cursos e treinamentos. Além dessa "consolidação" de saberes, proporcionada pelas formações, o conhecimento acerca dessas ferramentas se dá, de forma mais efetiva, na prática docente, ou seja, em sala de aula, com os alunos.

Os docentes que atuam no ensino superior podem ter um pouco mais de facilidade em relação aos do ensino básico e técnico para dar continuidade às suas 
atividades acadêmicas pela educação virtual, na medida em que a maioria dos discentes da graduação já tem alcançado sua própria autonomia de alguma forma. Conforme Arruda (2020. p. 10), "no ensino superior é possível perceber menos resistências à implementação de tecnologias digitais no processo de ensino e aprendizagem, sobretudo por atenderem pessoas adultas[...]".

Nesse sentido, o referido trabalho buscou coletar e analisar, por meio de um questionário on-line aplicado aos professores do ensino básico (fundamental e médio), técnico e superior do Brasil, as tecnologias digitais utilizadas por eles para garantir que o processo de ensino-aprendizagem não ficasse estagnado durante a pandemia da Covid-19, bem como as dificuldades encontradas nessa inserção. Dessa forma, o estudo está dividido da seguinte maneira: na segunda seção, são apresentados trabalhos correlatos; a terceira seção, por sua vez, dispõe dos procedimentos metodológicos da pesquisa; a quarta seção expõe os resultados e discussões do questionário aplicado; e, por fim, na quinta seção, são descritas as considerações finais e direções futuras deste estudo.

\section{TRABALHOS CORRELATOS}

Embora o ERE seja uma realidade nova para a maioria dos alunos e educadores, os pesquisadores já estão investigando as práticas pedagógicas dos professores das escolas, instituições e universidades no contexto da pandemia da Covid-19. Alinhados a essa visão, o estudo realizado por Lucas e Moita (2020), aborda o ensino efetivado por professores do estado da Paraíba durante a pandemia e objetiva refletir sobre os impactos do ERE em suas práticas pedagógicas. Os dados do estudo de caso foram coletados por meio de um questionário elaborado no Google Forms, que foi aplicado por meio de link a 105 professores de distintas áreas do conhecimento que trabalham em escolas públicas ou privadas, no ensino médio e/ou nos anos finais do ensino fundamental das redes municipal, estadual ou federal.

Os resultados obtidos apontaram uma diversidade de práticas realizadas por meio das TDICs, uma parte em conformidade com o modus operandi do ensino tradicional e outra buscando superá-lo. Segundo os autores, essas práticas podem proporcionar mais autonomia ao aluno, novas formas de comunicação entre os atores educacionais e aquisição de novas aprendizagens sobre o uso pedagógico desses recursos com potencial para modificar o ensino no contexto de pós- pandemia, quando voltarmos ao "novo normal" do ensino presencial.

Por fim, o trabalho de Deus et.al (2020), investigou como o ERE vem sendo conduzido pelos professores da área de Ciência da Computação no Brasil. Para isso, foi elaborado um questionário eletrônico, respondido por 137 professores de 69 instituições 
de ensino brasileiras. Os resultados obtidos abrangem os impactos observados e as estratégias que vêm sendo praticadas por tais profissionais. Em geral, foi possível observar que o ERE proporcionou uma ruptura no ensino de Ciência da Computação, como a falta de estratégia pedagógica e a ausência de experiência no ensino remoto. Muitos problemas são decorrentes da pandemia, mas a ausência de uma gestão eficiente da crise, por parte das entidades políticas, aliada à desigualdade social, tornou o ERE mais desafiador aos professores de Ciência da Computação no Brasil.

As pesquisas mencionadas são relevantes e condizentes com a proposta deste trabalho. No entanto, as mesmas não possuem enfoque exclusivo no uso de tecnologias digitais e educacionais nas práticas pedagógicas pelos professores do ensino básico, técnico e superior no contexto da pandemia da Covid-19. Sendo assim, este trabalho tem como diferencial a análise dos impactos e dos desafios enfrentados pelos professores no Brasil com o uso das Tecnologias da Informação e Comunicação (TICs), dos objetivos, da justificativa, do público-alvo, além da importância da Licenciatura em Computação/Informática no ERE.

\section{PROCEDIMENTO METODOLÓGICO}

Este trabalho foi realizado com base em levantamento bibliográfico para a construção teórica. Conforme Moresi et al. (2003, p. 5), "[...] a pesquisa bibliográfica fornece instrumental analítico para qualquer outro tipo de pesquisa[...]". Ademais, caracteriza-se por ser uma pesquisa exploratória pela utilização de um questionário on-line disponibilizado aos docentes dos ensinos básico, técnico e superior, para um melhor entendimento sobre os sujeitos estudados. Dessa maneira, visa "proporcionar maior familiaridade com o problema, com vistas a torná-lo mais explícito ou a constituir hipóteses[...]" (GIL, 2010, p. 41).

$\mathrm{O}$ artigo também se configura como um estudo de caso, pois se refere a um grupo específico: os professores. De acordo com Prodanov e Freitas (2013, p. 60), "o estudo de caso consiste em coletar e analisar informações sobre determinado indivíduo, uma família, um grupo ou uma comunidade, a fim de estudar aspectos variados de sua vida, de acordo com o assunto da pesquisa [...]".

Os dados foram coletados por meio de um questionário on-line desenvolvido na plataforma Google Forms, sendo divulgado publicamente pelos meios de comunicação, tais como: Instagram, Facebook, WhatsApp e e-mail. O período de coleta dos dados ocorreu entre os dias 06 de maio e 18 de junho de 2021, na qual se obtiveram 158 respostas. 0 questionário supracitado foi dividido em três seções, a saber: na primeira, continha o Termo de Consentimento Livre e Esclarecido (TCLE); na segunda, possuía 06 (seis) questões referentes à atuação profissional (localização e profissão) do docente; e na terceira, a apresentação das 09 (nove) questões relacionadas ao uso de tecnologias digitais e 
educacionais em sala de aula no período da pandemia, totalizando 15 (quinze) questões com perguntas abertas, fechadas e de múltipla escolha, o que possibilitou, dessa forma, uma abordagem dos dados tanto em aspectos quantitativos como qualitativos. Assim, foi possível uma visão melhor da familiaridade e dificuldades dos professores na utilização das tecnologias digitais e educacionais nas práticas pedagógicas, suas expectativas, interesse na participação de formação e treinamentos, bem como suas concepções acerca do Licenciado em Computação neste período de pandemia.

\section{RESULTADOS E DISCUSSÕES}

Por meio do questionário aplicado, foi possível observar, de modo geral, a atuação profissional, localização, identificação de gênero, categoria de ensino e disciplinas ministradas pelos professores no período de pandemia. No que se refere ao gênero, 55,7\% corresponderam ao gênero feminino e 44,7\% ao masculino. Via de regra, foram identificados 15 estados: Pará (124), São Paulo (7), Minas Gerais (4), Paraná (3), Mato Grosso (3), Bahia (3), Mato Grosso do Sul (2), Goiás (2), Santa Catarina (2), Distrito Federal (2), Maranhão (2), Ceará (1), Piauí (1), Paraíba (1), Rio de Janeiro (1) e Rio Grande do Sul (1). O Gráfico 1 apresenta os estados cujos professores participaram do questionário.

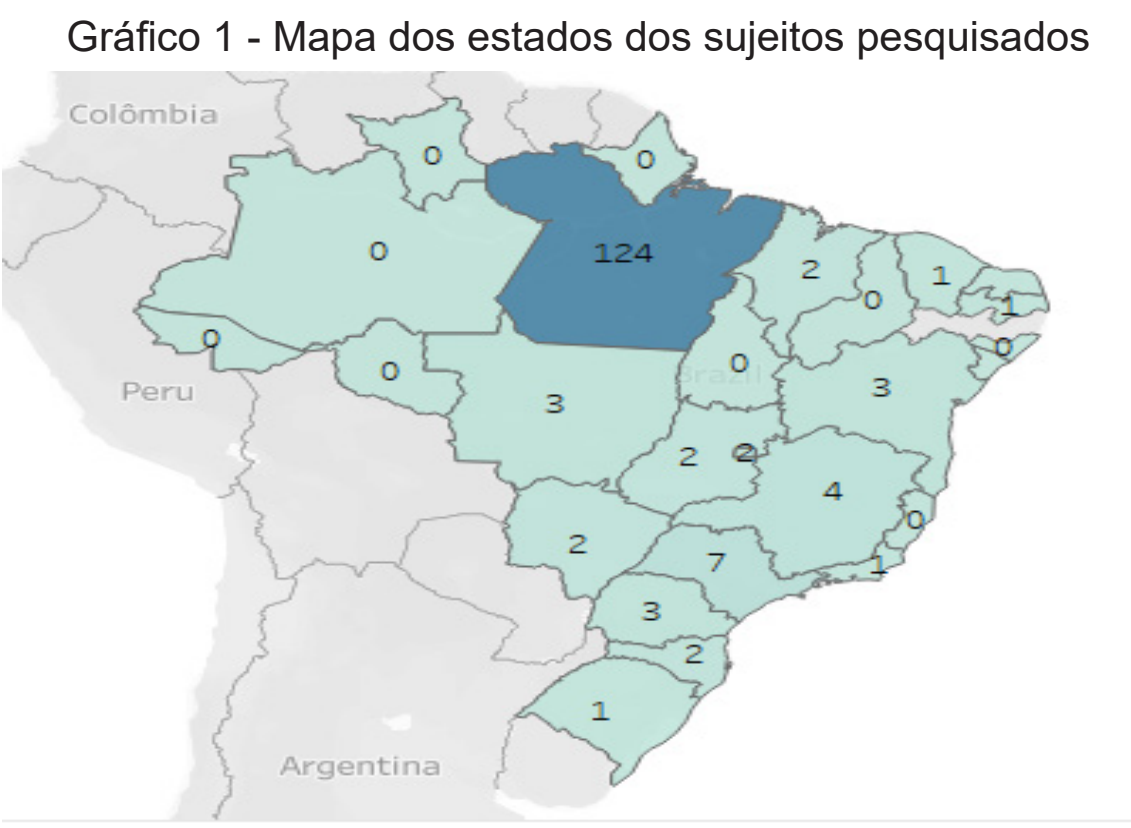

Fonte: Autoria própria (2021).

As cidades correspondentes foram: Aurora do Pará, Ananindeua, Belém, Belo Horizonte, Castanhal, Capitão Poço, Cuiabá, Cametá, Campinas, Camboriú, João Pessoa, Paragominas, Londrina, Rio de Janeiro, São Paulo, entre outras. 


\subsection{Atuação Profissional}

A atuação profissional foi dividida em 6 perguntas, entre as quais, 3 já haviam sido mencionadas no tópico anterior, e as demais estão compostas da seguinte forma: (4) Em qual(is) das categorias a seguir você se enquadra? (5) A escola em que você trabalha se enquadra em qual(is) das categorias? (6) Qual(is) o(s) componente(s) curricular(es) que você ministra?

O Gráfico 2, apresenta os resultados da pergunta 4, cujo objetivo foi buscar, também, a identificação dos professores que atuam em mais de um nível de ensino.

\section{Gráfico 2 - Categoria dos professores por níveis de ensino}

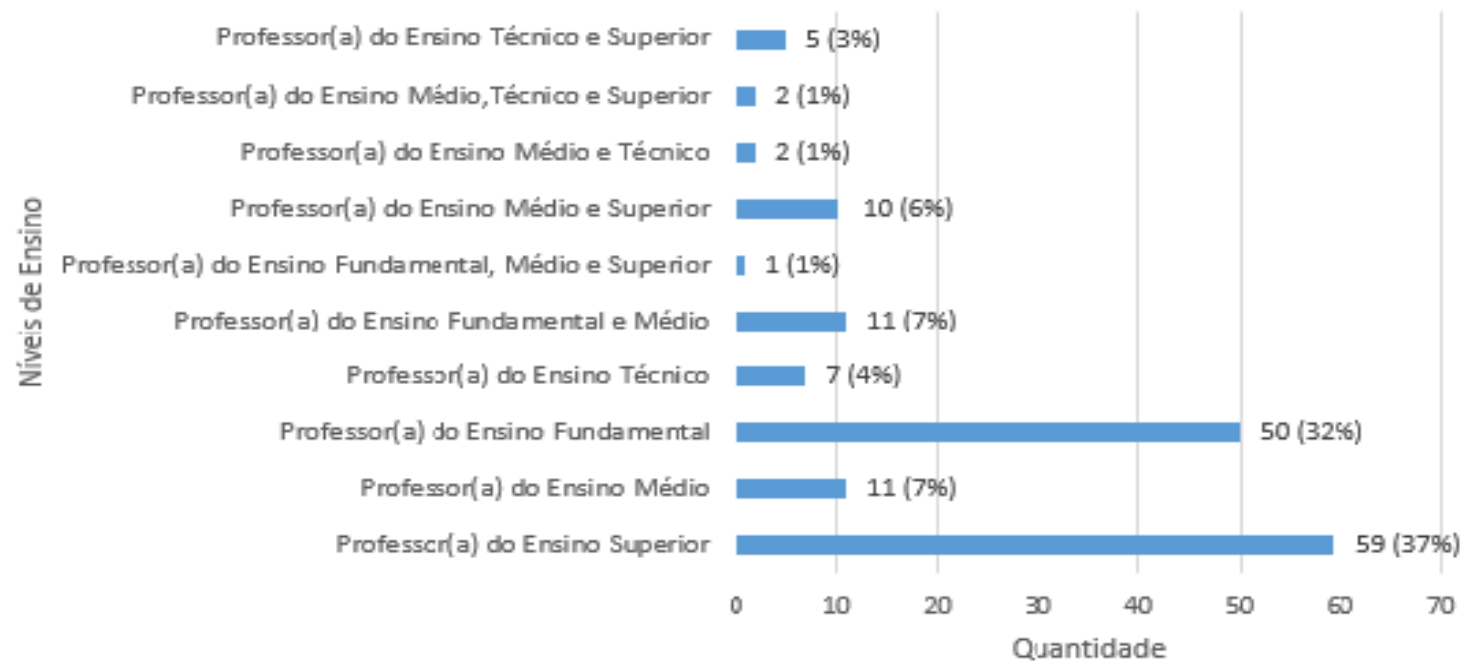

Fonte: Autoria própria (2021).

O Gráfico 2 mostra a categoria dos professores por nível de ensino: $37 \%$ dos docentes responderam atuar no ensino superior; 32\%, no fundamental; no médio, a atuação docente representa 7\%; e, no técnico, 4\%. Observa-se que a maioria dos participantes corresponde aos professores do ensino superior, seguidos dos profissionais do fundamental. É notável, ademais, a atuação dos docentes em dois ou mais níveis de ensino.

No que se refere à rede de atuação desses profissionais, 84,2\% trabalham em escolas públicas; $16,5 \%$ responderam atuar em escolas privadas, seguidas da Secretaria de Educação, da Escola Internacional para Sustentabilidade (EIS) e do Serviço Nacional de Aprendizagem Rural (Senar), com 0,6\% cada. Dessa forma, nota-se que grande parte dos professores que participaram deste estudo trabalha em escolas da rede pública.

Aúltima pergunta desta seção foi sobre qual(is) disciplina(s) ministrada(s) pelo(a) professor(a). Como resultado, 24,78\% são professores de Matemática; estão, em segundo lugar, os professores de Informática (20,9\%); a disciplina de Português consta em terceiro (16,5\%); o componente História corresponde a 15,8\%, estando em quarto lugar, seguido 
de Geografia (14,6\%), Artes (9,5\%), Educação Física (7\%), Biologia (5,1\%), Física (3,8\%) e Filosofia (2,5\%). Além disso, outras disciplinas identificadas foram: Química, Literatura, Língua Estrangeira, Sociologia, Ciências, Ensino Religioso, Administração, Libras, Redação e algumas outras referentes aos cursos de áreas da Computação, Zootecnia, Agronomia e Engenharia Florestal. Diante desse contexto, é possível identificar a diversidade de disciplinas ministradas remotamente e alcançadas nesta pesquisa.

\subsection{O uso das tecnologias digitais e educacionais em sala de aula}

Para coletar informações sobre o uso das tecnologias digitais e educacionais em sala de aula, esta seção utilizou nove perguntas mostradas no quadro abaixo:

Quadro 1 - Perguntas utilizadas no questionário sobre o uso das tecnologias digitais e educacionais em sala de aula

\begin{tabular}{|c|c|c|}
\hline ID & PERGUNTAS & TIPO DE PERGUNTA \\
\hline 07 & $\begin{array}{l}\text { A escola em que você trabalha realizou algum treinamento ou encontro } \\
\text { pedagógico para que o professor fosse preparado para as aulas a } \\
\text { distância durante a pandemia da Covid-19? }\end{array}$ & Múltipla escolha \\
\hline 08 & Você tem interesse em participar de uma formação e/ou capacitação? & Múltipla escolha \\
\hline 09 & $\begin{array}{l}\text { Você já utilizava algumas ferramentas/tecnologias educacionais na sala de } \\
\text { aula? }\end{array}$ & Múltipla escolha \\
\hline 10 & $\begin{array}{l}\text { Quais os recursos tecnológicos utilizados por você na realização das suas } \\
\text { atividades durante a pandemia da Covid-19? }\end{array}$ & Aberta \\
\hline 11 & $\begin{array}{l}\text { Quais foram as dificuldades encontradas por você no uso das tecnologias } \\
\text { digitais nas suas atividades durante a pandemia da Covid-19? }\end{array}$ & Aberta \\
\hline 12 & $\begin{array}{l}\text { Na sua opinião, a existência de um profissional da área da Licenciatura } \\
\text { em Computação poderia ter ajudado os professores no período inicial da } \\
\text { pandemia da Covid-19, com as ferramentas tecnológicas educacionais? }\end{array}$ & Múltipla escolha \\
\hline 13 & Com relação à pergunta anterior, justifique a sua resposta. & Aberta \\
\hline 14 & $\begin{array}{l}\text { Relacione o grau de frequência de uso das ferramentas tecnológicas } \\
\text { abaixo na realização das atividades remotas no período da pandemia da } \\
\text { Covid-19. }\end{array}$ & Múltipla escolha \\
\hline 15 & $\begin{array}{l}\text { Qual é o meio oficial para o contato que você, professor, está utilizando } \\
\text { com os alunos? }\end{array}$ & Caixa de seleção \\
\hline
\end{tabular}

Fonte: Autoria própria (2021).

No tocante à presença de treinamentos ofertados pela escola, instituição ou universidade em que atuam no início da pandemia referente a questão sete com $74,1 \%$ dos docentes responderam ter recebido treinamento, sendo a maioria dos professores que atuam no ensino superior, $32,3 \%$, e $16,43 \%$, no ensino fundamental; aproximadamente, 
os que informaram não terem recebido treinamento foram $25,9 \%$. Na questão oito, com relação à participação em treinamento e/ou capacitação, a maioria, com 89,2\%, disse ter interesse e 10,8\% responderam que não. Nota-se que a maioria recebeu treinamentos ofertados pelas escolas no início da pandemia, bem como tem interesse em participar de uma capacitação para melhor atender sua clientela neste período.

Na questão nove, $82,3 \%$ dos docentes informaram que utilizaram ferramentas tecnológicas em sala de aula; $16,5 \%$ disseram que não utilizaram; e 1,2\% dos docentes afirmaram que usaram algumas vezes. Referente à questão doze, dos recursos tecnológicos utilizados pelos docentes no período da pandemia, os mais mencionados foram: Google Meet, seguido do celular/smartphone, WhatsApp, notebook, computador, Google Classroom, Google Forms, internet e Moodle. Também foram citados outros recursos, como: lousa digital, Microsoft Teams, Mentimeter, Jamboard, Ambiente Virtual de Aprendizagem (AVA), SIGAA, Kahoot, GitHub, Telegram, Streamyard, Zoom, jogos on-line, AnswerGarden, Canva, Prezi, Quizzes, Blackboard, OBS Studio, BigBlueButton, Loom, Maps.me, aplicativo Duolingo, portfólio digital, podcasts, entre outros. Assim, nos resultados dessa questão, pôde-se identificar que os professores manusearam diversos recursos tecnológicos, tanto em equipamentos como em programas e ferramentas on-line, disponíveis na rede.

A pergunta onze se referiu aos desafios que os professores tiveram com o uso das tecnologias digitais nas atividades das aulas remotas durante a pandemia da Covid-19. O Quadro 2 apresenta as principais dificuldades relatadas por eles, e a coluna ID representa a identificação do professor com sua respectiva resposta ao lado, na coluna respostas.

De acordo com ele, foi possível observar algumas das dificuldades enfrentadas pelos profissionais durante esse período. No entanto, tiveram outras, tais como: construção de material audiovisual para expor as devidas explicações aos discentes; cansaço mental devido às horas que passavam em frente ao computador elaborando, editando e aplicando atividades das aulas; manutenção da motivação e participação dos alunos; feedback por parte dos alunos, que nem sempre ocorria; conhecimento acerca do uso das diversas ferramentas digitais e adequação às aulas práticas; a inserção de aplicativos nas aulas em pouco tempo; ajuste da tecnologia para a disciplina; e ausência de software apropriado em algumas situações.

Quadro 2 - As principais dificuldades dos professores referentes ao uso de tecnologias

\begin{tabular}{|l|l|}
\hline ID & RESPOSTAS \\
\hline 03 & "A falta de conhecimentos dos pais e alunos sobre a utilização das tecnologias." \\
\hline 10 & $\begin{array}{l}\text { "A falta de capacitação para gravação de vídeos (a desenvoltura na frente da câmera), devido não } \\
\text { utilizar esse método anteriormente para as aulas." }\end{array}$ \\
\hline 17 & "Aprender de forma abrupta o uso de ferramentas do Google." \\
\hline
\end{tabular}




\begin{tabular}{|l|l|}
\hline 29 & "A dificuldade é que nem todos os alunos têm acesso à internet." \\
\hline 37 & "Adequação destas tecnologias ao contexto das aulas." \\
\hline 58 & "Não ter uma orientação de como ministrar as aulas remotas; essa foi a maior dificuldade." \\
\hline 65 & "Adaptar o conteúdo das formações presencial para a formação a distância." \\
\hline
\end{tabular}

Fonte: Autoria própria (2021).

Nesse caso, alguns professores comentaram que deveria ter tido o apoio institucional para uma formação ou capacitação, no sentido de compreender o manuseio das ferramentas e organizar o tempo para a preparação das aulas, pois levam muito mais tempo que no formato presencial, além de não terem sido capacitados anteriormente, entre outras dificuldades. Diante desses relatos, apenas oito professores comentaram que não apresentaram dificuldades, mas que seus alunos sim, por não terem acesso à internet, ao computador e, ainda, não terem o conhecimento acerca do uso das tecnologias digitais e educacionais, o que dificultou as aulas remotas.

Sobre a décima segunda questão, quando questionados se o profissional Licenciado em Computação/Informática poderia ter auxiliado no início da pandemia, com a orientação ao uso das ferramentas tecnológicas educacionais, a maioria, 81,6\%, disse que sim; 9,5\% responderam que não auxiliaria; e 8,9\% não souberam responder. Para Santos, Hinterholz e Silva (2017), "o curso de Licenciatura em Computação é o que atende à demanda de formação de professores capazes de operar no uso e desenvolvimento de tecnologias para a educação, bem como ensinar a Computação na escola."

Na décima terceira pergunta, foi solicitado que os docentes justificassem a resposta anterior sobre a importância do profissional da Licenciatura em Computação/ Informática no que concerne à ajuda aos professores no período inicial da pandemia da Covid-19, com a orientação ao uso das ferramentas tecnológicas educacionais. O Quadro 3 apresenta as principais respostas sobre a relevância desses profissionais. A coluna ID representa a identificação do docente com sua respectiva resposta ao lado, na coluna respostas.

Os professores que participaram da pesquisa acreditam que seria enriquecedor e essencial um profissional dessa área, especificamente, um Licenciado. Contudo, alguns professores da Computação e Tecnologia já trabalhavam e utilizavam esses recursos educacionais em suas aulas antes da pandemia. Eles mencionaram que não tiveram nenhum tipo de dificuldade, mas que seus colegas de trabalho enfrentaram diversos desafios para procurar e manusear as ferramentas adequadas para o conteúdo da disciplina, porquanto eles nunca as haviam utilizado em suas atividades com alunos, além da falta de uma formação para capacitá-los quanto às suas inserções. 
Quadro 3 - Resposta dos docentes sobre a importância do profissional da Licenciatura em Computação/Informática no contexto da pandemia.

\begin{tabular}{|c|l|}
\hline ID & \multicolumn{1}{c|}{ RESPOSTAS } \\
\hline 03 & $\begin{array}{l}\text { "Um profissional da área é muito importante para auxiliar no processo de elaboração e execução das } \\
\text { aulas remotas." }\end{array}$ \\
\hline 04 & $\begin{array}{l}\text { "O papel desse profissional é propiciar o conhecimento, por meio da mediação dos recursos tecno- } \\
\text { lógicos, envolvendo toda a comunidade escolar nesse processo, para que as ações tenham bom } \\
\text { êito." }\end{array}$ \\
\hline 06 & "Eles poderiam apoiar a formar os outros professores." \\
\hline 17 & $\begin{array}{l}\text { "Como as pessoas tiveram de aprender a lidar com TDICs, o professor Licenciado em Informática } \\
\text { deveria ter sido figura central nos treinamentos." }\end{array}$ \\
\hline 40 & $\begin{array}{l}\text { "É fundamental um profissional na área de Computação no processo de criação do material didático } \\
\text { de aplicação à distância. Isso agiliza a construção e compartilhamento do material proposto." }\end{array}$ \\
\hline 99 & $\begin{array}{l}\text { "Para apresentar as principais ferramentas, aplicativos e softwares que poderiam ser utilizados em } \\
\text { sala com os alunos." }\end{array}$ \\
\hline 124 & "São profissionais essenciais, principalmente no contexto em que estamos vivendo." \\
\hline 125 & $\begin{array}{l}\text { "Pois muitos professores ainda têm bastante dificuldade em manusear as ferramentas tecnológicas, } \\
\text { e um profissional da área ajudaria muito." }\end{array}$ \\
\hline
\end{tabular}

Fonte: Autoria própria (2021).

Nesse sentido, a falta do Licenciado em Computação/Informática e de preparação para a utilização das TICs gerou algumas dificuldades aos professores, como também aos alunos no início das aulas remotas. Uma minoria dos participantes disse que esse profissional não era o essencial, o ideal seria um pedagogo.

Para as respostas da pergunta 14 foi utilizado um grau de frequência com escala de 1 (não se aplica), 2 (nunca), 3 (raramente), 4 (frequentemente) e, por último, a escala 5 (sempre), a fim de identificar o nível de utilização das ferramentas tecnológicas, como: celular, tablet, computador de mesa e computador portátil. O Gráfico 3 mostra o grau de utilização dessas tecnologias nas aulas remotas no período da pandemia.

Gráfico 3 - Grau de frequência da utilização das ferramentas tecnológicas

14. Relacione o grau de frequência de uso das ferramentas tecnológicas abaixo na realização das atividades remotas no período da pandemia do COVID-19.

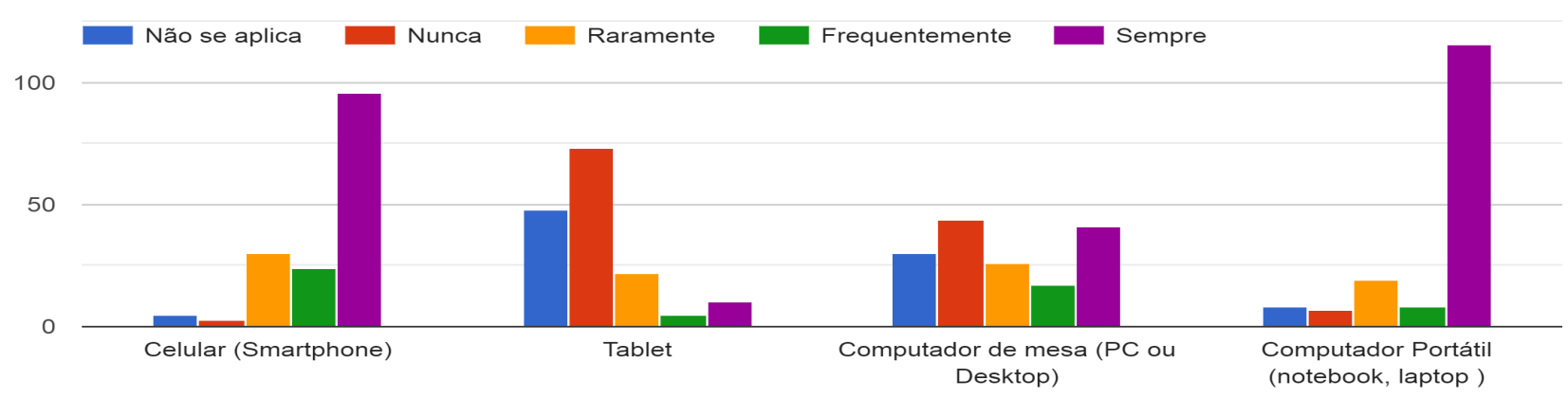

Fonte: Autoria própria (2021). 
De acordo com o Gráfico 3, as tecnologias mais usadas pelos professores durante as aulas remotas foram o computador e o celular. Na categoria "computador portátil", como notebook e laptop, os graus de frequência foram: não se aplica (8); nunca (7); raramente (19); frequentemente (8); e sempre (116). Por sua vez, na categoria "celular", foram: não se aplica (2); nunca (3); raramente (30); frequentemente (24); e sempre (96).

A última pergunta está relacionada ao meio oficial utilizado para o contato do professor com os alunos. A maioria, representada por 50,6\%, usou o aplicativo de mensagens WhatsApp; $14,6 \%$ fizeram o uso do SIGAA; e 12\%, do e-mail. Foram citadas outras plataformas e aplicativos, tais como: Telegram, Microsoft Teams, Google Classroom, AVA, Google Meet, Moodle, contato telefônico, Facebook e o portal da instituição. Alguns professores mencionaram que o principal meio de comunicação com os alunos ainda foi de forma tradicional, por meio de atividades impressas e de cartazes com os avisos que eram disponibilizados.

Todos os dados elencados acima são significativos, uma vez que apresentam o contexto do docente de diferentes estados e níveis de ensino com relação à utilização dos recursos tecnológicos e educacionais em suas práticas pedagógicas no cenário pandêmico. Percebeu-se, também, que a maioria dos sujeitos da pesquisa recebeu treinamento no início da pandemia, especialmente, nos níveis superior e fundamental. Além disso, o interesse dos docentes em participarem de capacitações foi demonstrado pela maioria deles.

Quanto à importância do Licenciado em Computação, os professores destacaram que ele seria de grande ajuda no que tange às capacitações e orientações no uso desses recursos, pois, como resultado desta análise, observou-se que há diversas ferramentas tecnológicas das quais os professores precisam se apropriar em um curto período de tempo, para dar continuidade ao ensino de maneira remota, tanto em equipamentos como em programas disponíveis na rede.

\section{CONSIDERAÇÕES FINAIS}

Foi explorado neste trabalho que o uso das tecnologias se tornou cada vez mais relevante e necessário em diversos espaços e setores da sociedade, notadamente, no campo educacional, visto que, neste período de pandemia da Covid-19, os professores precisaram se adaptar a uma realidade desconhecida, a qual muitos não estavam habituados, o que exigiu buscar inovações, formações e treinamentos. Diante deste cenário, o objetivo em coletar e analisar as informações relacionadas à utilização e aos desafios dos professores com relação às ferramentas digitais para o prosseguimento do ensino-aprendizagem foi alcançado, posto que esses sujeitos tiveram à disposição um arsenal tecnológico tanto em equipamentos como em programas e ferramentas disponíveis.

Os principais desafios citados foram o acesso à internet por parte dos alunos, a falta de uma formação mais específica na área, ou de um profissional de Licenciatura em 
Informática, e adequação dessas tecnologias ao contexto das aulas. Portanto, foi possível observar que o engajamento dos professores é notório no que concerne à procura constante por novas ferramentas tecnológicas de ensino e por metodologias de ensino, buscando possibilidades de atender os discentes de uma forma eficaz nesta conjuntura de ensino remoto. Pretende-se, em trabalhos futuros, realizar uma oficina on-line sobre as TDICs no contexto educacional para os docentes que atuam no ensino médio e técnico, pois foram os níveis de ensino que apresentaram menor porcentagem de treinamentos.

\section{REFERÊNCIAS}

ARRUDA, E. P. Educação remota emergencial: elementos para políticas públicas na educação brasileira em tempos de Covid-19. Revista de Educação a Distância, São Paulo, v. 7, n. 1, p. 257-275, 2020.

BARANAUSKAS, M. C. C; VALENTE, J. A. Tecnologias, Sociedade e Conhecimento. Revista NIED, Campinas, v. 1, p. 1-5, 2013. Disponível em: https://www.nied.unicamp.br/ revista/index.php/tsc/article/view/118/96. Acesso em: 3 mar. 2021.

DEUS, W. S.; FIORAVANTI, M. L.; DE OLIVEIRA, C. D.; BARBOSA, E. F. Emergency Remote Computer Science Education in Brazil during the Covid-19 Pandemic: Impacts and Strategies. Revista Brasileira de Informática na Educação, São Paulo, v. 28, p. 1032-1059, 2020.

GIL, Antônio Carlos. Como elaborar projetos de pesquisa. 4. ed. São Paulo: Atlas, 2010.

LUCAS, L. M.; MOITA, F. M. Ensino Remoto Emergencial (ERE): impactos na prática pedagógica durante a Covid-19. São Paulo: Educitec, 2020.

MORESI, Eduardo et al. Metodologia da pesquisa. Revista da Universidade Católica de Brasília, Brasília, v. 108, n. 24, p. 5, 2003.

OLIVEIRA, Ariane Xavier de; MELLO, Diene Eire de; FRANCO, Sandra Aparecida Pires. Práticas de ensino com o uso de tecnologias digitais: o papel da formação docente. Revista Teias, Rio de Janeiro, v. 21, n. 60, p. 75-90, 2020. Disponível em: https://www.e-publicacoes. uerj.br/index.php/revistateias/article/view/48627/32434. Acesso em: 10 mar. 2021.

PRODANOV, C. C.; FREITAS, E. C. Metodologia do trabalho científico: método e técnicas de pesquisa e do trabalho acadêmico. 2. ed., Novo Hamburgo: Feevale, 2013.

SANTOS, W. O.; HINTERHOLZ, L. T.; SILVA, C. C. V. Licenciatura em Computação: Desafios e Oportunidades na Perspectiva do Professor. In: VI CONGRESSO BRASILEIRO DE INFORMÁTICA NA EDUCAÇÃO (CBIE). Recife, 2017. Anais [...] Recife: UFR, 2017.

Recebido em 06 de outubro de 2021 Aprovado em 25 de novembro de 2021 